\title{
Bending Testing and Characterization of Surrogate Nuclear Fuel Rods Made of Zircaloy-4 Cladding and Aluminum Oxide Pellets
}

\author{
Hong Wang ${ }^{\mathrm{a}}$, Jy-An John Wang ${ }^{\mathrm{b} 1}$ \\ ${ }^{a}$ Corresponding author. wangh@ornl.gov, 865-574-5601 (phone), 865-574-6098 (fax), Materials \\ Science and Technology Division, Oak Ridge National Laboratory, One Bethel Valley Road, \\ Oak Ridge, Tennessee 37831, USA \\ b wangja@ornl.gov, Materials Science and Technology Division, Oak Ridge National \\ Laboratory, One Bethel Valley Road, Oak Ridge, Tennessee 37831, USA
}

\begin{abstract}
Behavior of surrogate nuclear fuel rods made of Zircaloy-4 (Zry-4) cladding with alumina pellets under reversed cyclic bending was studied. Tests were performed under load or moment control at $5 \mathrm{~Hz}$. The surrogate rods fractured under moment amplitudes greater than $10.16 \mathrm{Nm}$ with fatigue lives between $2.4 \times 10^{3}$ and $2.2 \times 10^{6}$ cycles. Fatigue response of Zry-4 cladding was characterized by using flexural rigidity. Degradation of flexural rigidity was shown to depend on the moment and the prefatigue condition of specimens. Pellet-to-pellet interface (PPI), pellet-tocladding interface (PCI), and pellet condition affect surrogate rod failure. Debonding of PPI/PCI and pellet fracturing all contribute to surrogate rod bending fatigue. The effect of sensor spacing

\footnotetext{
${ }^{1}$ Notice: This manuscript has been authored by UT-Battelle, LLC under Contract No. DE-AC05-00OR22725 with the U.S. Department of Energy. The United States Government retains and the publisher, by accepting the article for publication, acknowledges that the United States Government retains a non-exclusive, paid-up, irrevocable, worldwide license to publish or reproduce the published form of this manuscript, or allow others to do so, for United States Government purposes. The Department of Energy will provide public access to these results of federally sponsored research in accordance with the DOE Public Access Plan (http://energy.gov/downloads/doe-publicaccess-plan).
} 
on curvature measurement using three-point deflections was studied; the method based on effective gauge length is effective in sensor spacing correction. The database developed and the understanding gained in this study can serve as input to analysis of SNF (spent nuclear fuel) vibration integrity.

\section{Introduction}

Shock and vibration are among the normal conditions of transportation that need to be studied for licensing of SNF (spent nuclear fuel) transportation. The licensee is required to assure that there will be no loss or dispersal of SNF, no significant increase in external surface radiation levels, and no substantial reduction in the effectiveness of the SNF package [1]. Transient shock and steady vibrations can impose substantial loading to SNF rods resulting in mechanical fatigue. The fatigue is exacerbated in the case of high burnup (HBU, $>45 \mathrm{GWd} /$ MTU) SNF. As the burnup of the SNF increases, a number of changes occur that may affect the performance of the SNF and its cladding in storage and transportation. These changes include increased cladding corrosion layer thickness, increased cladding hydrogen content, increased cladding creep deformation, increased fission gas release, and formation of a high burnup structure at the surface of the fuel pellets. As a result, the HBU SNF rods are susceptible to premature failure, and their mechanical behavior must be carefully understood and controlled in order to satisfy the regulatory requirements, as discussed above.

Bending is a prevailing loading mode for SNF rods in both the hypothetical accident drop and normal conditions of transport [2]. In the latter, forced vibrations originating from the roadvehicle interaction are applied to the SNF rods through the endplates in the rod assembly. The magnitude of vibration depends on the road condition and the dynamics of the vehicle system. 
The possibility of fuel release in the scenarios mentioned above relies on the capability of the cladding to withstand the dynamic loading so as to contain the SNF.

In fact, a large number of experiments have been conducted to investigate the mechanical response of cladding related to in-reactor service, SNF reconfiguration, and storage. The fuel cladding has been studied using an axial tensile test, ring-tension tests, a ring-compression test, and a biaxial tube burst test to investigate the effect of the stress state and to meet different requirements from applications. The relevant data on Zircaloy, including cold-worked stressrelief annealed (CWSR or SRA) Zircaloy-4 (Zry-4) and recrystallized (RXA) Zircaloy-2 (Zry-2), were reviewed by Greelhood et al. [3] and empirical equations developed to describe mechanical quantities (model parameters including elastic modulus, strength coefficient, strain hardening exponent, strain rate exponent, and uniform elongation) as a function of fast neutron fluence, temperature, cold-work, and so on. To understand the fatigue properties of cladding materials used in the reactor core, the cyclic fatigue of Zircaloy was studied under various loading conditions including tension and bending $[4,5,6]$. In a later study [7], it has been shown that irradiation reduces the fatigue life of all materials in the low cycle regime.

However, in all of these experimental efforts, fuel cladding was studied as a stand-alone material with no fuel pellets included. This is significant because the pellet-cladding mechanical interaction (PCMI) plays a paramount role in the response of fuel rod as demonstrated in related analyses of reactivity-initiated accident (RIA) [8,9]. The effect of the PCMI on the bending of fuel rods in a transportation environment is not clear. In a composite rod comprised of cladding and fuel pellets, stress state is further complicated by the stress gradient over the cross section. The understanding of bending response of fuel cladding under such complicated stress state is 
critical, especially considering high stress-state sensitivity and anisotropy of mechanical property of cladding materials such as CWSR Zry-4 [10,11].

The use of surrogate nuclear fuel rods is explored in this study to investigate the mechanical responses of CWSR Zry-4 cladding with aluminum oxide (alumina) pellets contained in which the PCMI is simulated by the interfaces between alumina pellets and Zry-4 cladding. The advantage of using surrogate rods is that testing parameters and testing materials are more controllable than tests using actual structures, which would need to be performed in hot cell as demonstrated in the recent activities at Oak Ridge National Laboratory (ORNL) $[12,13,14,15]$.

This report presents the experimental results of using surrogate rods made of the Zry-4 cladding and alumina pellets under monotonic and reversed cyclic bend loadings.

\section{Experimental Techniques}

\subsection{Testing system and specimen preparation}

The bending test system is composed of a U-frame testing setup for applying bending loads on the spent fuel rod specimen and a unit for measuring the curvature of the rod during bending [12,13,14]. Dual linear motors (Bose ElectroForce System Dual LM2 TB, MN) [16] are used to apply the forces symmetrically at two loading points. The U-frame setup converts the forces into a moment imposed on the rod specimen (Figure 1). To protect the rod from potential contact damage, two rigid sleeves or endcaps are mounted to the two end sections of rod by using a high strength epoxy (3M DP420, MN). ${ }^{2}$ The deformation of the rod is measured by three LVDTs

\footnotetext{
${ }^{2}$ Certain commercial equipment, instruments, or materials are identified in this paper in order to specify the experimental procedure adequately. Such identification is not intended to imply recommendation or endorsement by Oak Ridge National Laboratory, nor is it intended to imply that the materials or equipment identified are necessarily the best available for the purpose
} 
(linear variable displacement transformers). Use of the three LVDTs eliminates the effect of epoxy layers on the deformation measurement. The curvature generated by the compressive loads is designated as negative and that by tensile loads is designated as positive. As a result, tension is on -y side (below neutral axis) for a negative curvature and on $+y$ side (above neutral axis) for a positive curvature.

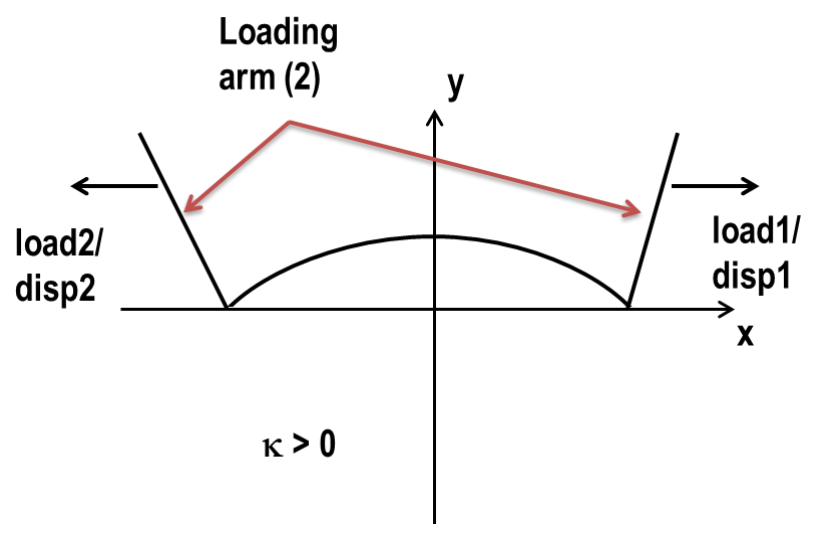

(a)

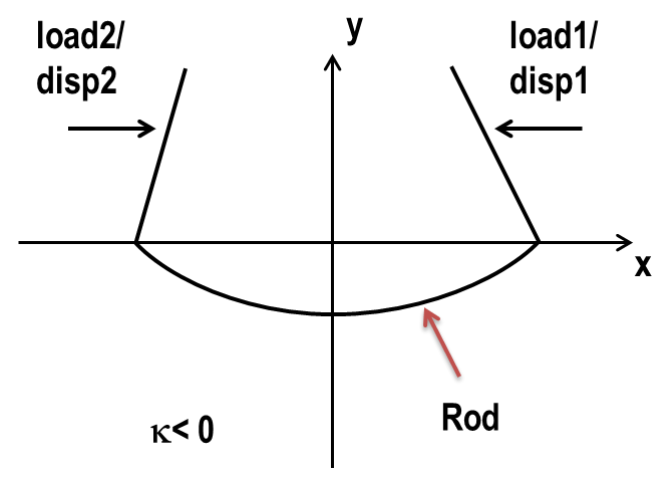

(b)

Figure 1. Bending of rod under loads or displacements applied by dual linear motors in (a) positive and (b) negative of curvature. 
Cladding specimens were prepared from Zry-4 tubes and had OD (outside diameter) $9.50 \mathrm{~mm}$, ID (inner diameter) $8.36 \mathrm{~mm}$, and length $152.40 \mathrm{~mm}$ [17]. Model material for fuel pellets was alumina cylinders measured with $7.94 \mathrm{~mm}$ in diameter and $15.24 \mathrm{~mm}$ in length. Hence, 10 alumina pellets were used in one specimen. A schematic of the surrogate rod is given in Figure 2. The specimen with endcaps installed has an overall length same as that of the cladding and a nominal gauge length of $50.80 \mathrm{~mm}$. The alumina pellets were prepared out of high temperature nonporous alumina rods purchased from McMaster-Carr. ${ }^{2}$ The pellet-cladding interaction was simulated by epoxy bonding using the epoxy same as in mounting the endcaps. In the following, designation ZRAPxx will be used for rods made of Zry-4 cladding and alumina pellets with epoxy bonding, and ZRAPMxx for the rod with same cladding and alumina pellets but no epoxy bonding; last two letters xx stand for specimen number.

(a)

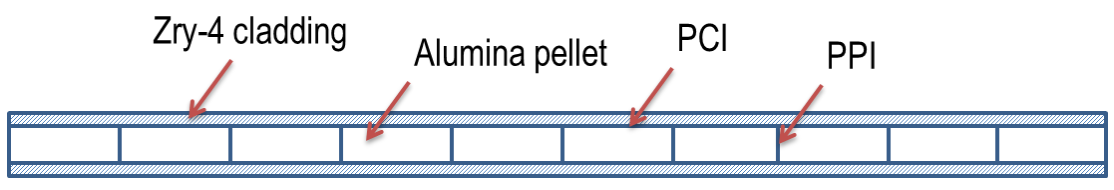

(b)

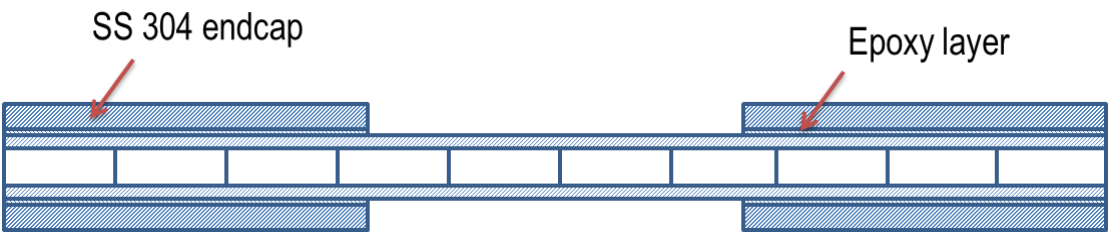

Figure 2. Schematic showing model rod when (a) un-capped and (b) capped; drawing not to the scale. $\mathbf{P C I}=$ pellet-to-cladding interface; $\mathrm{PPI}=$ pellet-to-pellet interface; $\mathbf{S S}=$ stainless steel. 


\subsection{Testing procedure and data processing}

Both monotonic testing and reversed cyclic testing were performed. The monotonic testing was conducted under displacement control. The displacement of each linear motor (or at each loading point of U-frame) was set at a rate of $0.2 \mathrm{~mm} / \mathrm{s}$ to $10.00 \mathrm{~mm}$ and back to $0 \mathrm{~mm}$ at the same rate. The maximum relative displacement at the two loading points was thus $20.00 \mathrm{~mm}$.

The fully-reversed cyclic bending was conducted under load control at $5 \mathrm{~Hz}$. The following load amplitudes were selected based on the monotonic tests, 100, 150, 175, 200, 250, and $300 \mathrm{~N}$. These loads would generate fatigue lives from several thousands to several millions of cycles. Online monitoring was enabled. Small amplitude low frequency $(0.05 \mathrm{~Hz}$ under displacement control) measurements were made at the specified cycles. The cyclic test stopped whichever of the following events occurred: (1) displacement channel of either linear motor was out of predetermined limits ( \pm 4 or $\pm 6 \mathrm{~mm}$ ), or (2) the accumulative cycle number exceeded 1 or 2 million.

The moment was calculated as

$M=F \times L$,

where $F$ is the averaged value of loads (load1 and load2) from the Bose dual motors, and $L$ is the loading arm length of U-frame, $101.60 \mathrm{~mm}$.

The curvature, $\kappa$, of rod was estimated by using deflections $d_{1}, d_{2}, d_{3}$ from three LVDTs according to the procedure outlined in Appendix. The curvature measurement can be affected by the contacts between the LVDT probes and the rod. This is mainly because the current LVDTs use disk-shaped probes and the sensor spacing $h$ in the curvature calculation would change in 
measurement or monitoring. The sensor spacing was corrected by $\Delta \mathrm{h}$ according to the correction procedure as discussed in Appendix.

Time series in moment and curvature were obtained from either online monitoring or measurement, which can be further converted into a moment-curvature loop as shown in Figure 3. The moment amplitude or half moment range $\Delta \mathrm{M} / 2$ can be expressed in terms of peak $\mathrm{M}_{\mathrm{p}}{ }^{+}$ and valley $\mathrm{M}_{\mathrm{p}}{ }^{-}$, as follows,

$\Delta \mathrm{M} / 2=\left(\mathrm{M}_{\mathrm{p}}^{+}-\mathrm{M}_{\mathrm{p}}^{-}\right) / 2$.

The curvature response of rod can be measured directly by peak $\kappa_{\mathrm{p}}{ }^{+}$, valley $\kappa_{\mathrm{p}}{ }^{-}$, amplitude $\Delta \kappa / 2$,

$\Delta \kappa / 2=\left(\kappa_{\mathrm{p}}^{+}-\kappa_{\mathrm{p}}^{-}\right) / 2$,

and offset $\kappa_{\text {offset}}$,

$\kappa_{\mathrm{offset}}=\left(\kappa_{\mathrm{p}}^{+}+\kappa_{\mathrm{p}}^{-}\right) / 2$,

Further characterization of rod response was made by using flexural rigidity $\mathrm{R}$, and hysteresis $\mathrm{U}_{\mathrm{M}}$ as defined by the following

$R=\Delta M / \Delta \kappa$,

$$
U_{M}=\oint M d \kappa
$$

The flexural hysteresis results from the curvature phase delay with respect to the external moment and mostly from the energy dissipation associated with the structural damages of rod. 


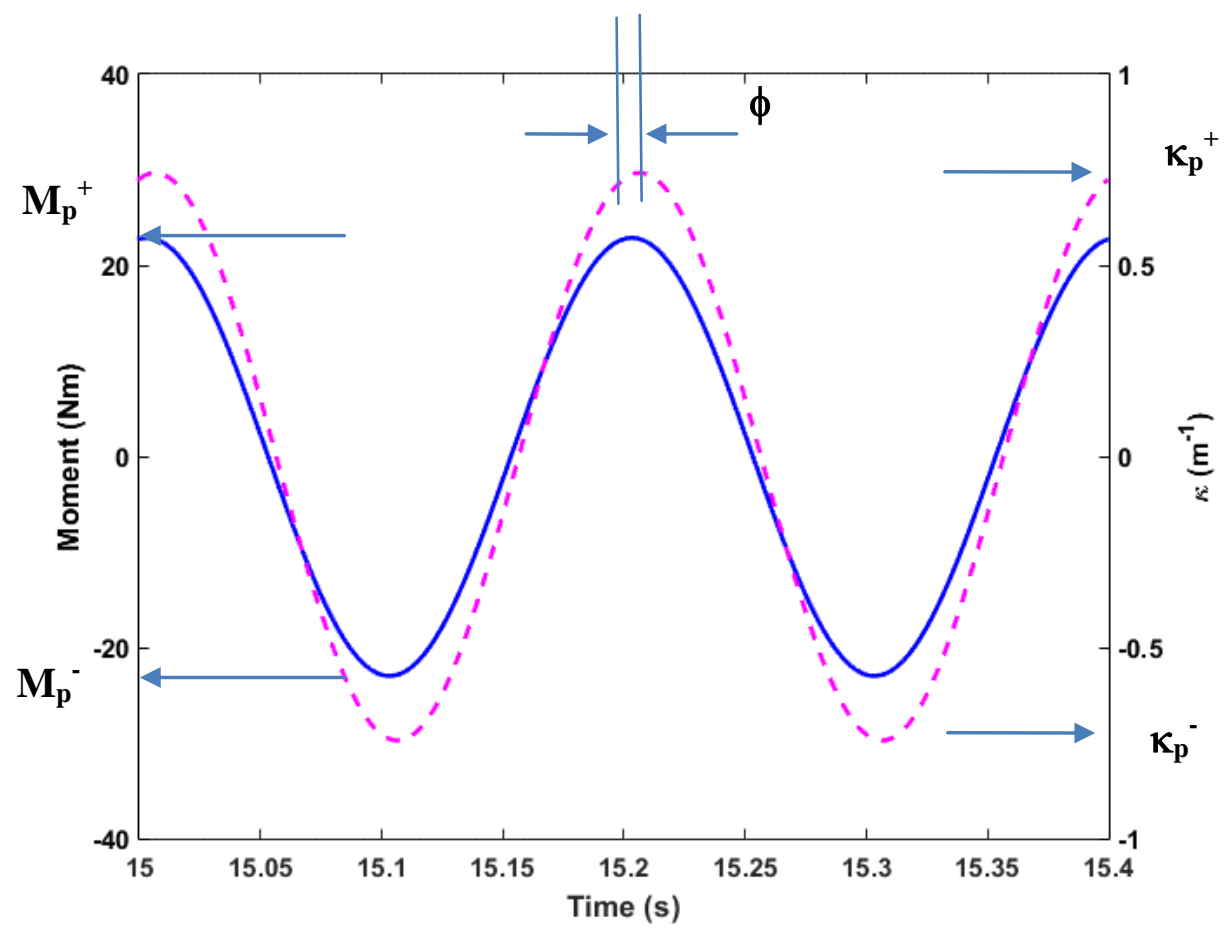

(a)

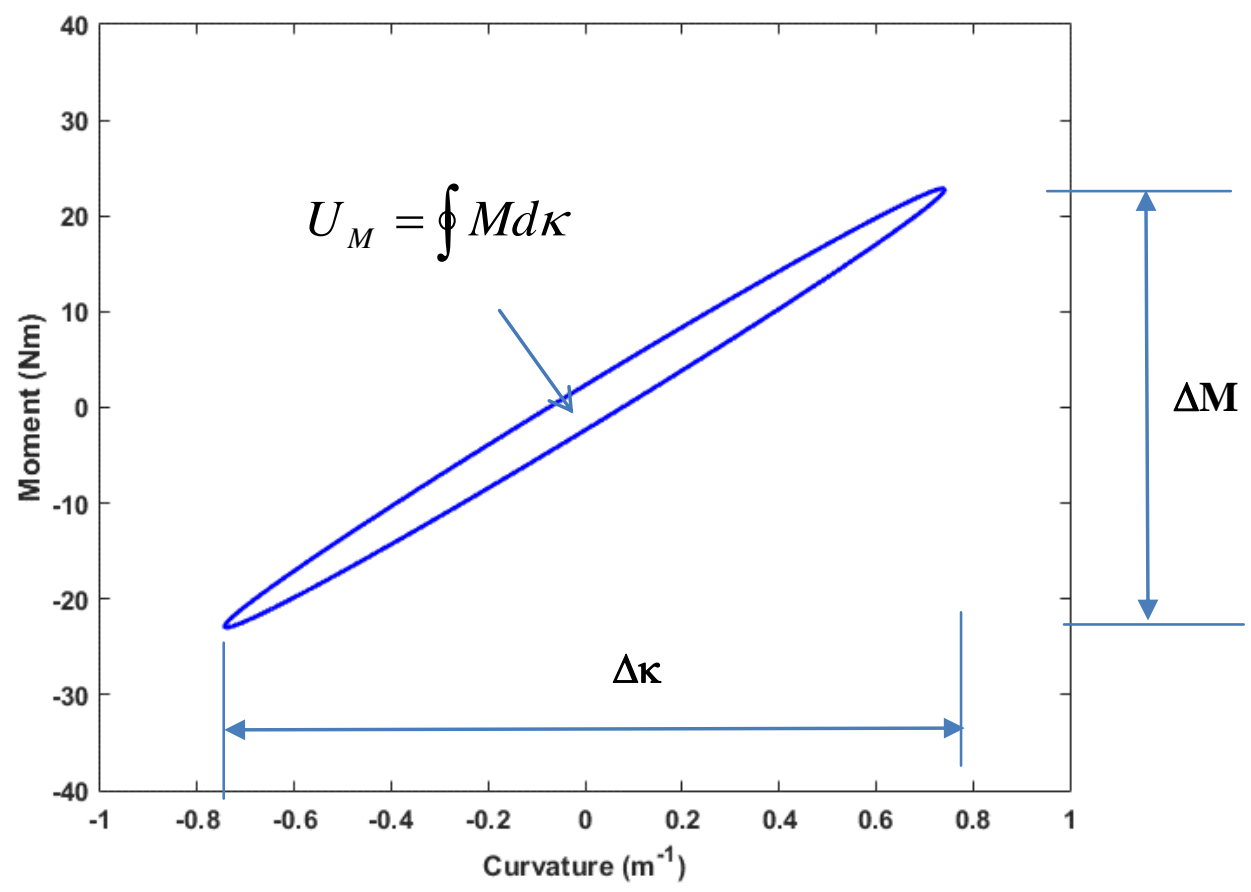

(b)

Figure 3. Quantities used in characterization of bending response of rod in (a) time domain and (b) moment-curvature (M-k) loop. 


\section{Experimental Results}

\subsection{Monotonic bending testing}

ZRAP01 and ZRAP12 were tested in the static bending condition whose results are presented in Figure 4 (a) along with that of ZRAPM01. The M- $\kappa$ curve was seen beginning with a short linear response and then a nonlinear response in the loading stage. Several small drops were observed before the peak load. Intermittent acoustic emissions were heard during the test, which may be caused by cracking of pellets. Apparently, those rods survived loading to the maximum input without failure. The unloading part of curves generally followed a slope similar to that of loading part before the local drops; therefore, the structural integrity of the rods was largely maintained.

The secant flexural rigidity (the ratio of instantaneous moment to instantaneous curvature) was calculated, and the results for the loading stage of three tests are given in Figure 4 (b). The rigidity curves generally exhibit a momentary decrease followed by a continuous decrease with decreasing rate. There is a distinct difference in rigidity responses between the rods with epoxy bonding and without epoxy bonding. A much lower level of rigidity was seen in the latter at a slower decrease rate because of the absence of epoxy bonding. 


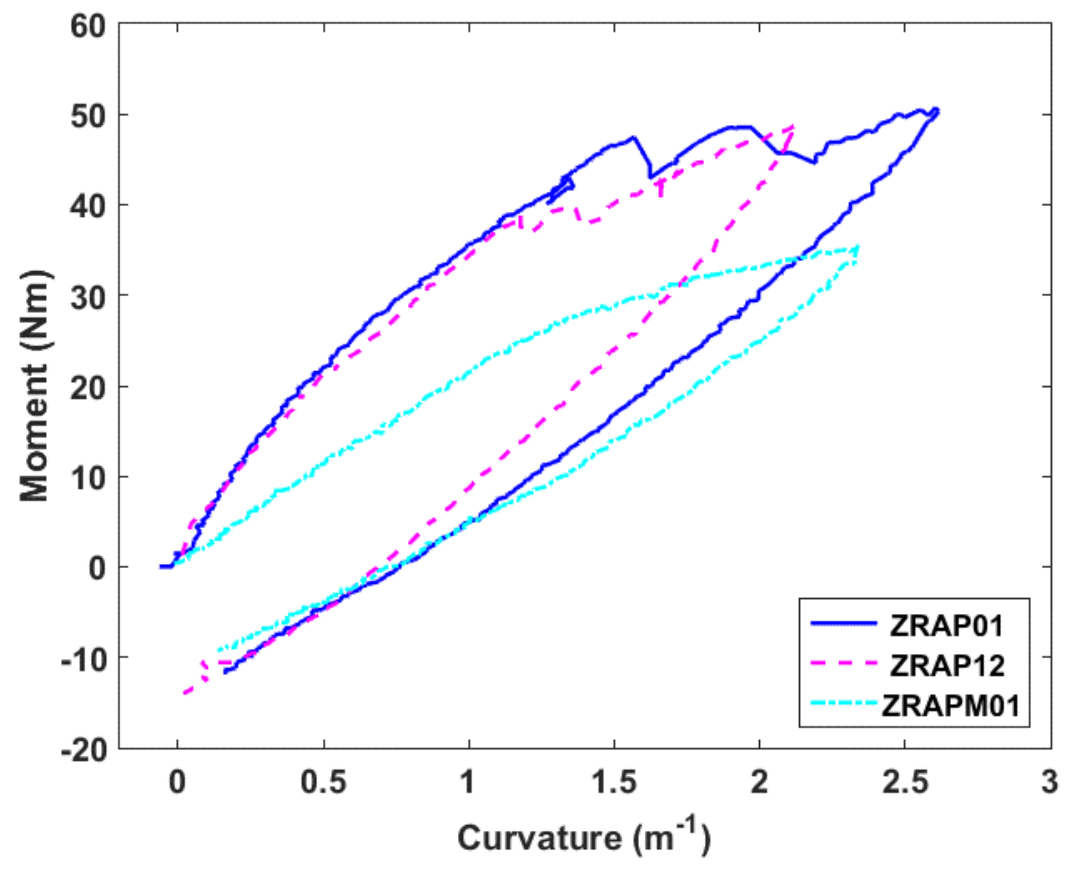

(a)

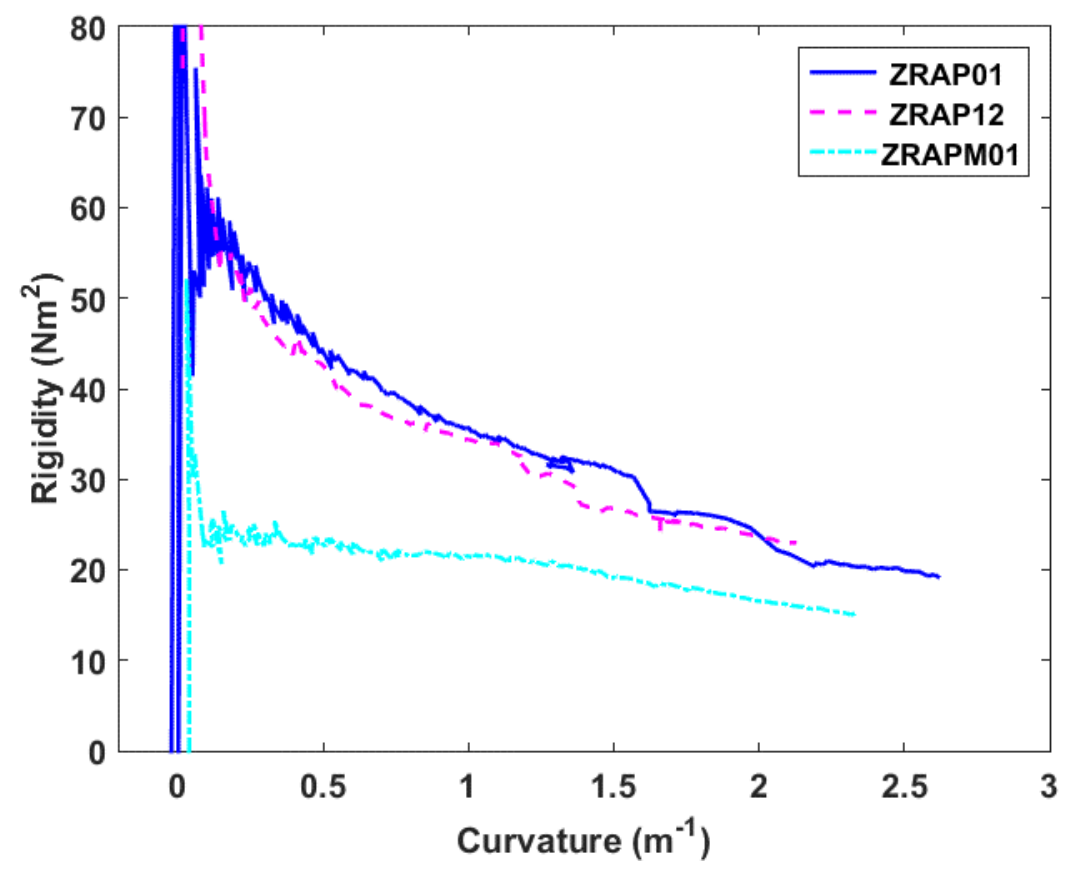

Figure 4. (a) Moment-curvature curves and (b) curves of secant flexural rigidity versus curvature for static bending tests of ZRAP01, ZRAP12 and ZRAPM01 under $0.2 \mathrm{~mm} / \mathrm{s}$ and maximum relative displacement of $20 \mathrm{~mm}$. The curvature was based on $\Delta \mathrm{h}=2.50 \mathrm{~mm}$. 


\subsection{Reversed cyclic bending}

\subsubsection{Fatigue life}

Failure occurred only when the moment amplitudes were greater than $10.16 \mathrm{Nm}$. The results on fatigue life of surrogate rods are summarized in Table 1 along with the failure mode that will be discussed in the following. Under $10.16 \mathrm{Nm}$, ZRAP02 did not show any sign of failure after more than a million cycles. Within the range of loads tested, the fatigue life of surrogate rods was found out to be ranged from $2.4 \times 10^{3}$ to $2.2 \times 10^{6}$ cycles, decreasing with increasing moment as expected. The difference in fatigue life was also seen between the rods under the same amplitude. For instance, a relatively long life was seen in ZRAP09 compared to ZRAP04, even though both were tested under same amplitude of $15.24 \mathrm{Nm}$. Such a difference is associated with the initial condition of the rods.

Table 1. Fatigue life and failure mode of reversed cyclic bending tests

\begin{tabular}{|c|c|c|c|c|}
\hline Spec. & $\begin{array}{l}\text { Load } \\
(\mathbf{N})\end{array}$ & $\begin{array}{l}\Delta \mathrm{M} / 2 \\
(\mathrm{Nm})\end{array}$ & $\begin{array}{l}\text { Cycles } \mathbf{N} \\
\text { or } \mathbf{N}_{f}\end{array}$ & Failure mode \\
\hline ZRAP02 & 100 & 10.16 & $1.3 \times 10^{6}$ & $\begin{array}{ll}\text { - } & \text { Used in system tuning } \\
\text { - } & \text { No failure, taken off stage }\end{array}$ \\
\hline ZRAP04 & 150 & 15.24 & $5.5 \times 10^{5}$ & $\begin{array}{l}\text { - Tripped of disp1 at }-4.000 \mathrm{~mm} \\
\text { - } \quad \text { Fractured on -y side near PPI in middle gauge section }\end{array}$ \\
\hline ZRAP09 & 150 & 15.24 & $2.2 \times 10^{6}$ & $\begin{array}{l}\text { - Tripped of disp1 at }-4.003 \mathrm{~mm} \text { by a short } 10 \mathrm{~Hz} \\
\text { loading } \\
\text { - Fractured on -y side on PPI in gauge section, close to } \\
\text { motor \#1 } \\
\text { - Pellet almost directly against cladding }\end{array}$ \\
\hline ZRAP10 & 175 & 17.78 & $5.9 \times 10^{4}$ & $\begin{array}{l}\text { - Tripped at }-5.002 \mathrm{~mm} \\
\text { - Fractured on -y side; failure on PPI in middle gauge } \\
\text { section }\end{array}$ \\
\hline ZRAP03 & 200 & 20.32 & $4.1 \times 10^{4}$ & $\begin{array}{l}\text { - Tripped at }+4.000 \mathrm{~mm} \\
\text { - } \quad \text { Fractured on }+y \text { side; failure on PPI within gauge } \\
\text { section but close to motor \#2 }\end{array}$ \\
\hline ZRAP11 & 200 & 20.32 & $4.2 \times 10^{4}$ & $\begin{array}{l}\text { - } \quad \text { Tripped at }-4.001 \mathrm{~mm} \\
\text { - } \quad \text { Fractured on -y side; failure near PPI in gauge }\end{array}$ \\
\hline
\end{tabular}




\begin{tabular}{|c|c|c|c|c|}
\hline & & & & section, but close to motor \#1 \\
\hline ZRAPI3 & 250 & 25.40 & $1.1 \times 10$ & $\begin{array}{l}\text { - } \text { Tripped at }+4.000 \mathrm{~mm} \\
\text { - Fractured on }+y \text { side; } 4 \mathrm{~mm} \text { crack found in gauge } \\
\text { section but near motor \#2. }\end{array}$ \\
\hline ZRAP15 & 250 & 25.40 & $2.4 \times 10^{3}$ & $\begin{array}{l}\text { Pre-tripped at }-4.000 \mathrm{~mm} \text {, around } 100 \text { cycles } \\
\text { Subsequent cycling tripped at }+6.000 \mathrm{~mm} \\
\text { - Fractured on }+y \text { side; failure on PPI in gauge section } \\
\text { but near motor } \# 2\end{array}$ \\
\hline ZRAP14 & 300 & 30.48 & $3.4 \times 10^{3}$ & $\begin{array}{l}\text { - Partial PCI bonding revealed } \\
\text { - Pre-tripped at }-4.000 \mathrm{~mm} \text { near } 100 \text { cycles Subsequent } \\
\text { cycling tripped at }-6.002 \mathrm{~mm} \\
\text { - } \text { Fractured on a PPI inside the endcap on motor } \# 2\end{array}$ \\
\hline
\end{tabular}

\subsubsection{Variation of curvature}

Both measurement and monitoring data sets were obtained in a cyclic test. The small-amplitude measurement data are very important in characterizing the response of rods and justifying the loading of system. However, the following discussion is focused on online monitoring.

The peak/valley values of $\kappa$ as a function of cycles are presented in Figure 5. Note that a cyclic test session usually takes some time to ramp to a designated level of amplitude. The monitoring data are not started from cycle one (for example, ZRAP14). In prefatigue, curvature peak/valley values increased proportionally to moment amplitudes. Two exceptions were observed for ZRAP10 and ZRAP15. The curvature of ZRAP10 was much larger than expected, even though the deflections varied proportionally to the moment amplitude. ZRAP15 experienced prefatigue tripping during the ramping stage, and the large curvature increase may be attributed to the damage induced by the large amplitude loading.

A steady peak/valley increase was generally observed in positive or negative direction with the number of cycles. The tertiary stage, in which the fatigue of curvature would be accelerated, was not well developed and only seen as a short tail in some tests with moment at least $20.32 \mathrm{Nm}$. 
The dominant steady stage of fatigue allows a linear relation between peak/valley $\left(\kappa_{\mathrm{p}}^{+}\right.$or $\left.\kappa_{\mathrm{p}}{ }^{-}\right)$ and $\log \mathrm{N}$ to be used in characterization, namely

$\kappa_{\mathrm{p}}^{+}=\mathrm{a} 1^{+} \times \log \mathrm{N}+\mathrm{a} 2^{+}$

$\kappa_{\mathrm{p}}{ }^{-}=\mathrm{a} 1^{-} \times \log \mathrm{N}+\mathrm{a} 2^{-}$.

where a1 represents the fatigue rate with respect to $\log \mathrm{N}$, a 2 the initial value measured at $\mathrm{N}=1$, and superscript + and - signify the peak and valley, respectively. The estimates and intervals of estimate with $95 \%$ confidence level are listed in Table 2 for the model parameters in Eq. (7). The a1 obviously measures the impact of fatigue depending on the moment amplitude. For ZRAP02 that was tested without failure, a negative $a 1^{+}$and a positive $a 1^{-}$were revealed. The decreasing curvature range of the rod may result from cyclic hardening of the cladding. On the other hand, the a2 was more directly related to the level of moment, although it was truly outstanding for ZRAP10 and ZRAP15.

The analysis also revealed a range of $\kappa_{\text {offset }}$ as shown in Table 3 . No trend of the offset with respect to moment amplitudes can be seen, which is understandable because $\kappa_{\text {offset }}$ largely measures the initial condition of a rod. Overall, the $\kappa_{\text {offset }}$ was limited and the maximum offset occurred in ZRAP15 because of the tripping event before the cyclic test. 


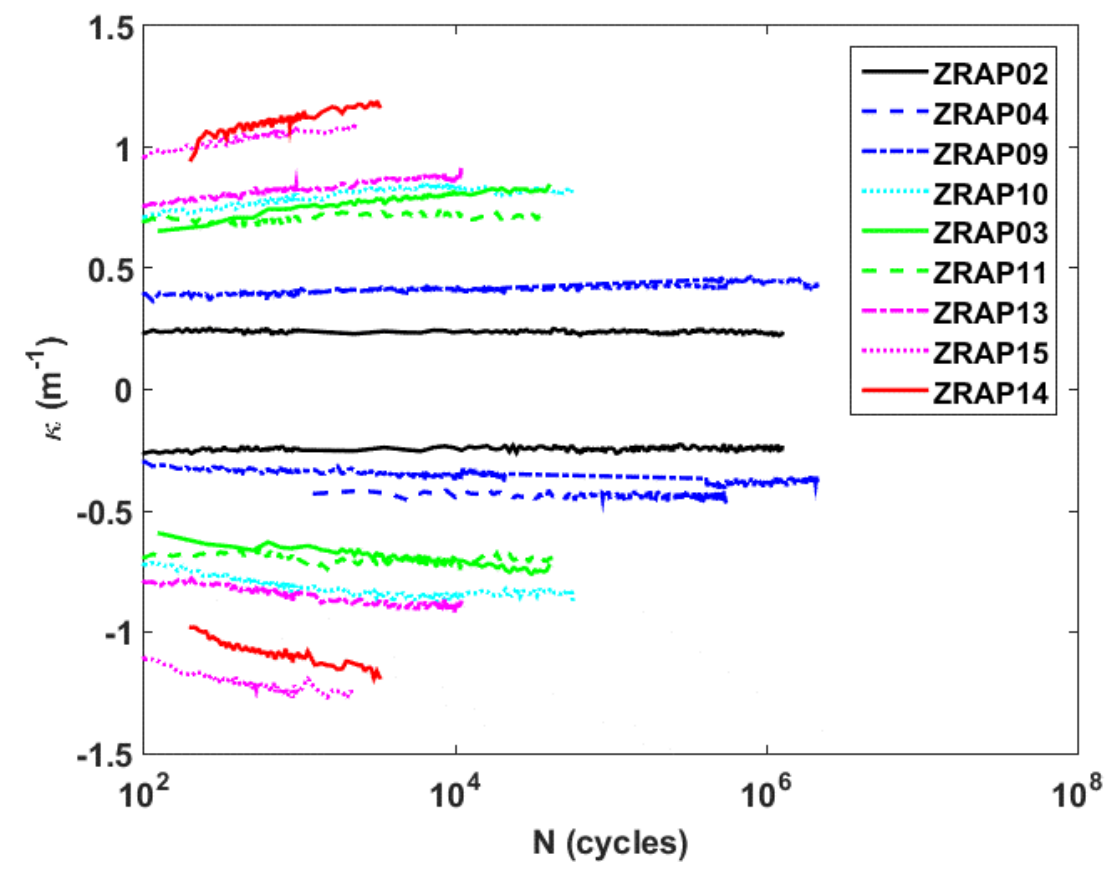

Figure 5. Variation of peak/valley values for $\kappa$ as a function of cycle number.

Table 2. Model parameters of curvature peak/valley values under various moment amplitudes

\begin{tabular}{|c|c|c|c|c|c|c|}
\hline & Spec. & $\Delta \mathrm{M} / 2(\mathrm{Nm})$ & $\overline{\mathrm{a1} 1^{+} \mathrm{o}}$ & a1 $^{-}\left(\mathrm{m}^{-1} /\right.$ decade $)$ & & or a2 $2^{-}\left(\mathrm{m}^{-1}\right)$ \\
\hline & & & Estimate & interval $^{a}$ & Estimate & interval $^{\mathbf{a}}$ \\
\hline$\kappa_{\mathrm{p}}^{+}$ & 2 & 10.16 & -0.002 & $-0.003,-0.002$ & 0.247 & $0.245,0.250$ \\
\hline & 4 & 15.24 & 0.008 & $0.006,0.010$ & 0.382 & $0.374,0.390$ \\
\hline & 9 & 15.24 & 0.015 & $0.014,0.016$ & 0.354 & $0.350,0.358$ \\
\hline & 10 & 17.78 & 0.040 & $0.036,0.044$ & 0.663 & $0.649,0.676$ \\
\hline & 3 & 20.32 & 0.058 & $0.054,0.062$ & 0.572 & $0.558,0.587$ \\
\hline & 11 & 20.32 & 0.016 & $0.013,0.019$ & 0.658 & $0.649,0.667$ \\
\hline & 13 & 25.40 & 0.056 & $0.053,0.058$ & 0.660 & $0.651,0.669$ \\
\hline
\end{tabular}




$\begin{array}{llllll}15 & 25.40 & 0.092 & 0.084,0.100 & 0.789 & 0.767,0.810 \\ 14 & 30.48 & 0.131 & 0.120,0.143 & 0.730 & 0.696,0.764\end{array}$

\begin{tabular}{ccccccc}
\hline$\kappa_{\mathrm{p}}^{-}$ & 2 & 10.16 & 0.002 & $0.001,0.003$ & -0.252 & $-0.255,-0.249$ \\
4 & 15.24 & -0.007 & $-0.009,-0.004$ & -0.403 & $-0.417,-0.389$ \\
9 & 15.24 & -0.015 & $-0.016,-0.015$ & -0.288 & $-0.292,-0.284$ \\
10 & 17.78 & -0.041 & $-0.046,-0.037$ & -0.677 & $-0.693,-0.662$ \\
3 & 20.32 & -0.058 & $-0.062,-0.054$ & -0.480 & $-0.495,-0.465$ \\
11 & 20.32 & -0.015 & $-0.018,-0.012$ & -0.644 & $-0.655,-0.634$ \\
13 & 25.40 & -0.059 & $-0.063,-0.056$ & -0.666 & $-0.677,-0.655$ \\
15 & 25.40 & -0.124 & $-0.139,-0.110$ & -0.874 & $-0.914,-0.834$ \\
14 & 30.48 & -0.129 & $-0.139,-0.118$ & -0.719 & $-0.749,-0.688$
\end{tabular}

${ }^{\mathrm{a}}$ Interval corresponds to $95 \%$ confidence level

Table 3. Curvature offsets of rods under various moment amplitudes

\begin{tabular}{cccc}
\hline Spec. & $\Delta \mathbf{M} / \mathbf{2}(\mathbf{N m})$ & \multicolumn{2}{c}{$\mathbf{\kappa}_{\text {offset }}\left(\mathbf{m}^{-\mathbf{1}}\right)$} \\
\cline { 3 - 4 } & & Mean & Std. \\
\hline 2 & 10.16 & -0.003 & 0.006 \\
4 & 15.24 & -0.007 & 0.008 \\
9 & 15.24 & 0.032 & 0.007 \\
10 & 17.78 & -0.009 & 0.008 \\
11 & 20.32 & 0.046 & 0.009 \\
13 & 20.32 & 0.008 & 0.009 \\
& 25.40 & -0.009 & 0.009
\end{tabular}




\subsubsection{Variations of flexural rigidity and hysteresis}

The value of fatigued rigidity is obviously related to the prefatigue level, and there is a wide range of prefatgue rigidity as shown in Figure 6. Such range of prefatigue rigidity is caused by the variable initial structural condition of rods and the level of moment. The effect of initial condition on the rigidity of rod was observed in small-amplitude measurement. For ZRAP09 and ZRAP10 that are located at top and bottom of fatigure plots, the measurements before fatigue test indeed revealed two extremes at 46 and $26 \mathrm{Nm}^{2}$. Meanwhile, the moment dependence of the rigidity became significant at the high level amplitudes, which was mainly attributed to the nonlinear phenonmenon as seen in Figure 4. For ZRAP02, the fatigue curve of rigidity was quite flat because no appreciable degradation occurred under such level of load. For those that failed, the decrease in rigidity was observed to be significant. The fatigue rate of ridigity is associated with the moment amplitude applied; a larger amplitude results in a greater decrease rate in rigidity.

Overall, the prefatigue hysteresis depends on moment amplitude, which is reasonable because a higher load produces a more sizable hysteresis loop in both loop amplitude and loop area. In cycling, the hysteresis itself increased in various extents and the rate of increasing became profound at the high amplitude. In the case of ZRAP14, the hysteresis was seen to surge from 6 to nearly $10 \mathrm{~N}$ in a short period of time because of high level loading. In general, there is an inverse correlation between the flexural rigidity and hysteresis. 

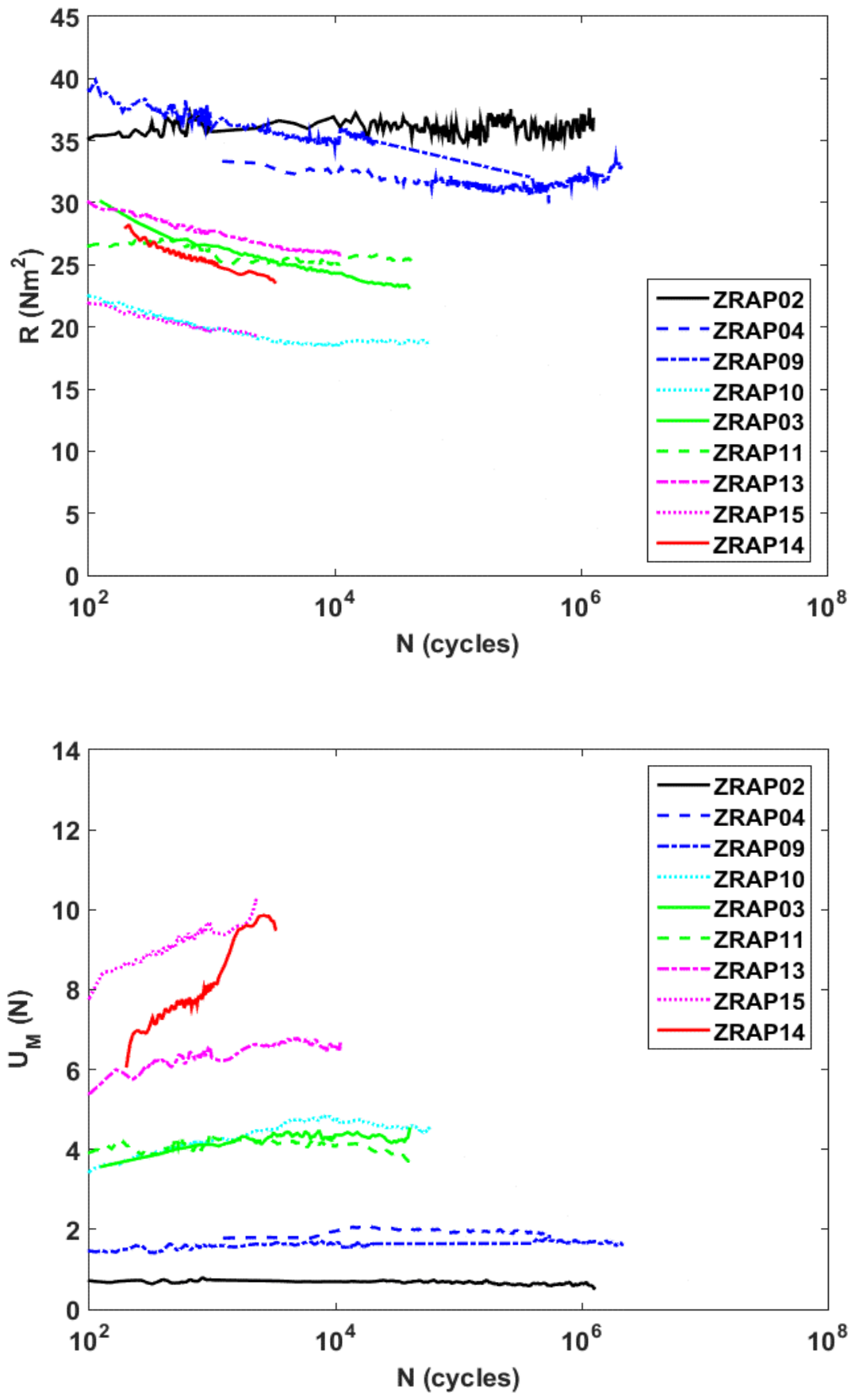

Figure 6. Variations of (a) flexural rigidity and (b) hysteresis as a function of cycle number. 


\subsubsection{Failure mode}

Specimens mostly failed within the nominal $(50.8 \mathrm{~mm})$ gauge section. Only ZRAP14 is unusual whose failure was located a little inside one of the endcaps (Table 1). Crack initiation site corresponded well with the sign of peak/valley values of disp1 or disp2. For example, a fracture of -y side is triggered by a large absolute value of valley as seen in ZRAP04. No direct relation was seen between the crack initiation site and the $\kappa_{\text {offset }}$. But it has been shown that a final fracture on -y side is indeed characterized by a rapid falling of curvature peak/valley and that on $+\mathrm{y}$ side is corresponding to a rapid rising of curvature peak/valley (Figure 5).

The interfaces dominate the failure of rod. Fracture surfaces of two fracture halves are shown in Figure 7 for ZRAP09. The fracture occurred on a PPI as evidenced by the exposed end faces of neighboring pellets. The crack initiation site was found to be located where the PCI epoxy layer is thinner than in other areas around the circumferential direction. Alumina pellets were cracked in the two areas subjected to the largest bending stress. Enlarged areas for side 1 and 2 suggest that the crack initiation site occurred near the inner surface of cladding; the flaw depth is less than 1/6 of wall thickness. A fracture with multiple crack initiation sites was observed for ZRAP15 as shown in Figure 8; the fracture was dominated again by the PPI. Fracture halves for sides 1 and 2 exhibited dual crack initiation sites as indicated by arrows near the external surface of cladding. The flaw appeared as a thin skin zone whose depth was less than 1/6 of wall thickness. Most of the local fracture surface near the crack initiation site features a river pattern behind the flaw. However, the beach marks are still identifiable far behind the crack initiation site as indicated by the arrows in the lower right corner of Figure 8 (a). The PCI void was seen in neighboring areas and the epoxy bonding was not uniform. The thickness of the PPI epoxy layer is approximately that of the PCI epoxy layer nearby. 
(a)

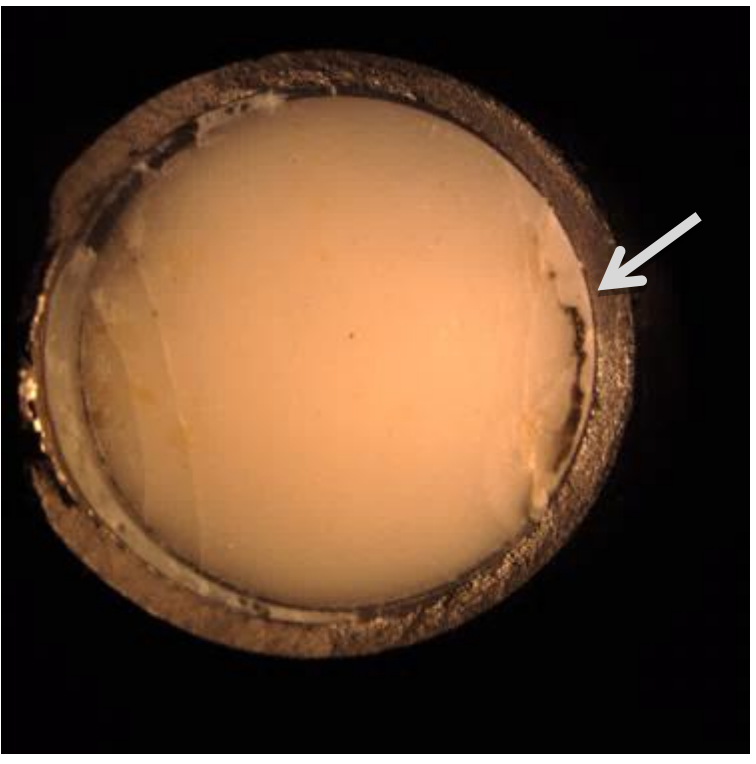

(b)
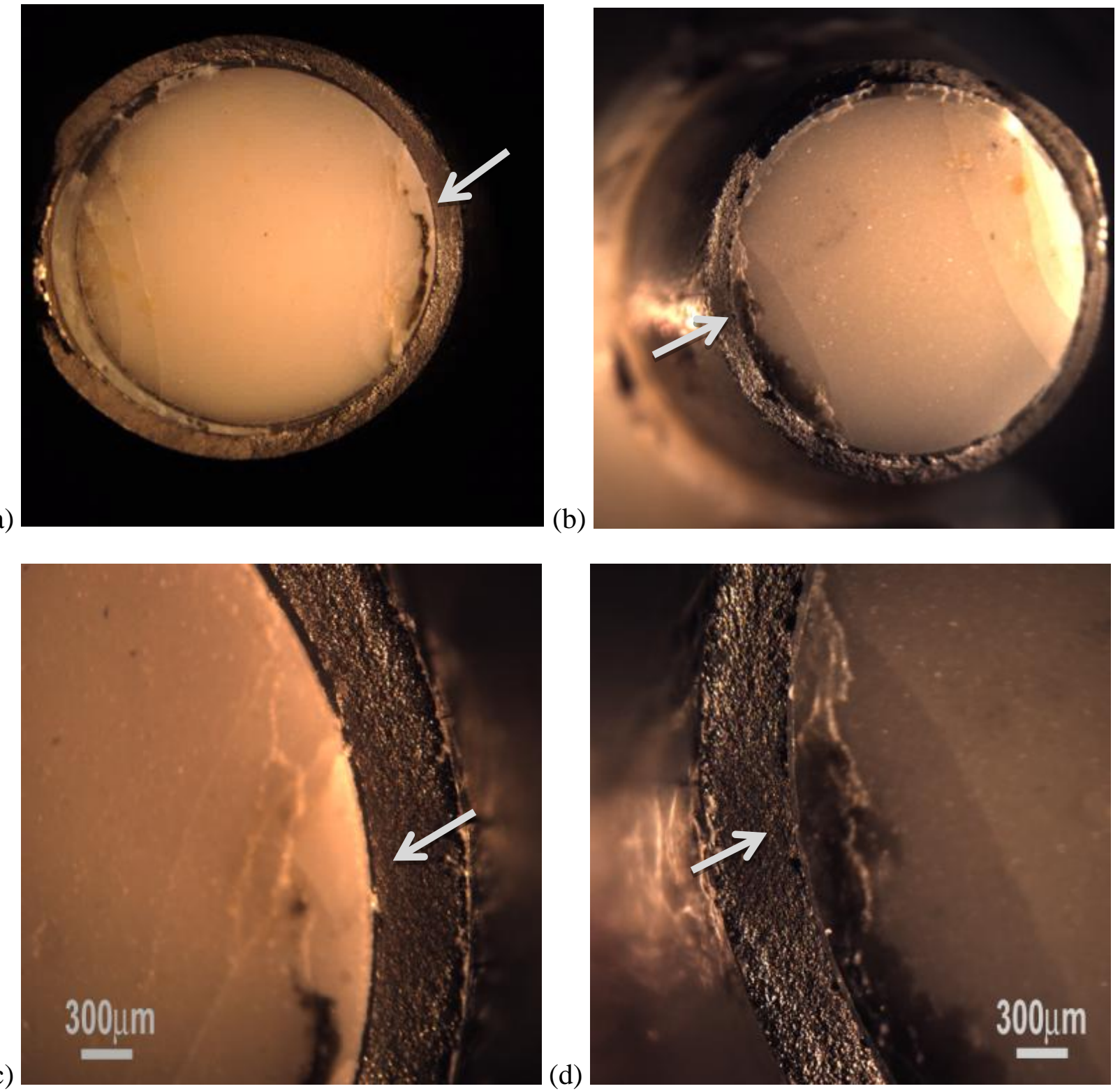

(d)

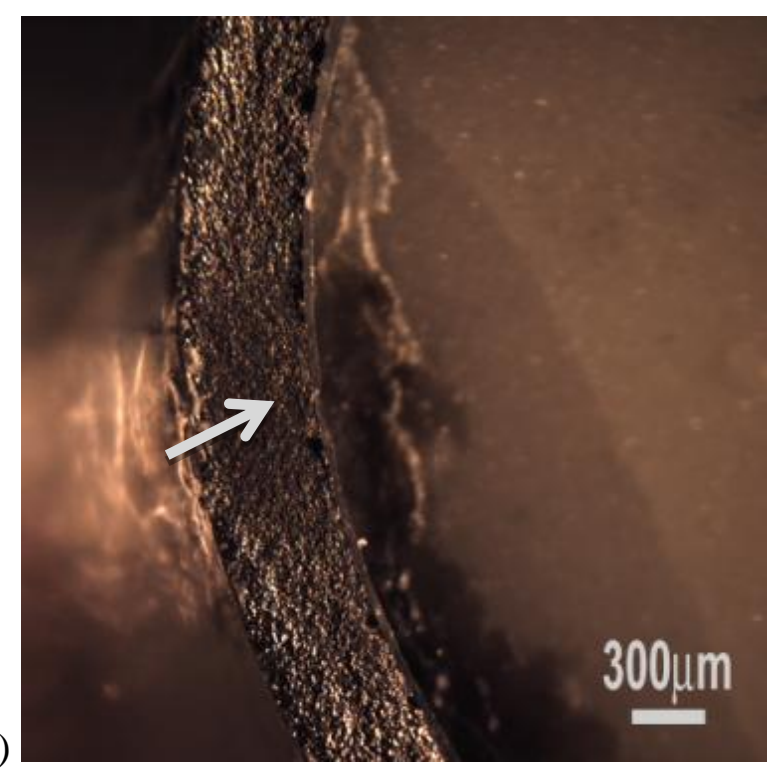

Figure 7. Fractured halves of ZRAP09 under $15.24 \mathrm{Nm}$ that failed at $2.2 \times 10^{6}$ cycles; failure occurred on a PPI. (a) side 1 and (b) side 2, failure origin located where the PCI epoxy layer is thinner than other PCI areas; alumina pellet cracked. Enlarged areas for (c) side 1 and (d) side 2 showing the failure origin on inner surface of cladding as indicated by arrows. 

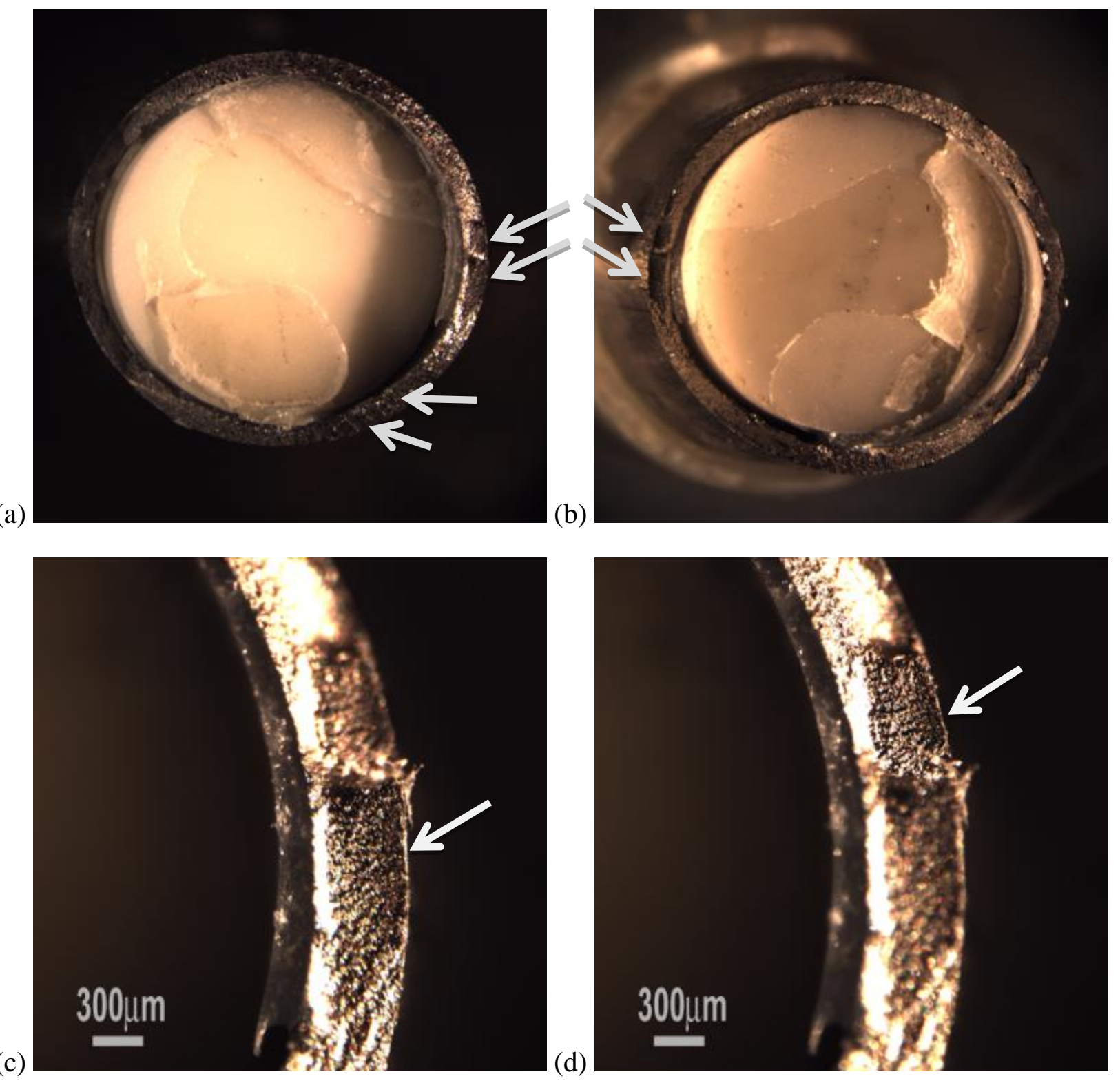

Figure 8. Fractured halves for ZRAP15 under $25.40 \mathrm{Nm}$ that failed at $2.4 \times 10^{3}$ cycles; failure occurred at PPI. (a) side 1 and (b) side 2 showing dual failure origins located near external surface of cladding. Enlarged areas are shown for (c) first failure origin and (d) second failure origin indicated by arrows. 


\section{Discussion}

\subsection{Effective gauge section}

It has been demonstrated that the effective half-gauge length is much larger than $25.4 \mathrm{~mm}$, ranging from 40 to $49 \mathrm{~mm}$ (Table 4). As a result of that the effective gauge length was extended into specimen end sections, the fracture could occur inside the endcaps as observed in ZRAP14. This is because the end sections of rod actually partake in the rotation and two imaginary hinges emerge at nearly the middle points of endcaps during the reversed bending. Overall, the $\Delta \mathrm{h}$ is lower than that suggested by calibration using the polycarbonate rod $(2.50 \mathrm{~mm})$. The results illustrate that the $\Delta \mathrm{h}$ is likely related to the moment amplitude, but the trend is hardly appreciable as the data points are scattering.

Table 4. Effective half-gauge length and sensor spacing correction in reversed cyclic bending tests.

\begin{tabular}{cccccc}
\hline Spec. & $\Delta \mathbf{M} / \mathbf{2}(\mathbf{N m})$ & \multicolumn{2}{c}{$\mathbf{L g} / \mathbf{2}(\mathbf{m m})$} & \multicolumn{2}{c}{$\Delta \mathbf{h}(\mathbf{m m})$} \\
\cline { 3 - 6 } & & Mean & Std. & Mean & Std. \\
\hline 2 & 10.16 & 46.335 & 0.644 & -0.156 & 0.476 \\
4 & 15.24 & 48.150 & 0.525 & 0.453 & 0.207 \\
9 & 15.24 & 49.089 & 0.804 & 0.952 & 0.413 \\
10 & 17.78 & 40.216 & 0.575 & 0.832 & 0.269 \\
3 & 20.32 & 44.631 & 0.321 & 1.650 & 0.117 \\
11 & 20.32 & 46.313 & 0.544 & 1.537 & 0.339 \\
13 & 25.40 & 48.206 & 0.351 & 1.060 & 0.125
\end{tabular}




\subsection{Degradation of flexural rigidity and fatigue mechanism}

The rigidity of rod can be written as

$R=E_{c} I_{c}+E_{p} I_{p}$

where $I_{c}$ and $I_{p}$ are moments of inertia of cladding and pellet, respectively; $E_{c}$ is elastic modulus of cladding, given as $80 \mathrm{GPa}$ for unirradiated Zry-4 with $50 \%$ cold work [3]; $\mathrm{E}_{\mathrm{p}}$ is elastic modulus of pellets and an effective modulus $\mathrm{E}_{\mathrm{pe}}$ shall be used for the alumina stack consisting of a specified number of alumina pellets and epoxy layers. By equaling the accumulated deformations of the components to the total deformation, the $\mathrm{E}_{\mathrm{pe}}$ can be expressed in terms of individual axial lengths and moduli as follows:

$$
\begin{gathered}
E_{p e}=\frac{L_{t o t a l}}{\sum_{i=1, N}\left(\frac{L_{p i}}{E_{p i}}+\frac{L_{e i}}{E_{e i}}\right)}, \\
L_{\text {total }}=\sum_{i=1, N}\left(L_{p i}+L_{e i}\right)
\end{gathered}
$$

where $\mathrm{L}_{\mathrm{pi}}$ and $\mathrm{L}_{\mathrm{ei}}$ are the lengths of $\mathrm{i}^{\text {th }}$ pellet and $\mathrm{i}^{\text {th }}$ epoxy layer in the axial direction. Based on the given dimensions of pellets, epoxy layer thickness, and equivalent gauge length, the model parameters can be taken as follows: for pellets, $\mathrm{L}_{\mathrm{pi}}=15.011 \mathrm{~mm}, \mathrm{E}_{\mathrm{pi}}=372 \mathrm{GPa}$; for epoxy layers, $\mathrm{L}_{\mathrm{ei}}=0.229 \mathrm{~mm}, \mathrm{E}_{\mathrm{ei}}=3.5 \mathrm{GPa}$; and $\mathrm{N}=6 . \mathrm{E}_{\mathrm{pe}}$ was estimated to be $144.2 \mathrm{GPa}$ by substituting the parameters into Eq. (9). A value of $47 \mathrm{Nm}^{2}$ was obtained for $\mathrm{R}$ by substituting the inertia moments $\left(\mathrm{I}_{\mathrm{c}}\right.$ and $\left.\mathrm{I}_{\mathrm{p}}\right)$ and moduli $\left(\mathrm{E}_{\mathrm{c}}\right.$ and $\left.\mathrm{E}_{\mathrm{pe}}\right)$ into Eq. (8). The $\mathrm{R}$ value is close to the 
rigidity in the range of curvatures in cyclic bending (Figure 4). It should be emphasized that the inherent interaction mechanism between cladding and pellets is more involved. A more comprehensive investigation on the topic can be found in a numerical research report [18].

Nevertheless, the flexural rigidity of rods degraded during the cyclic process, especially in those that failed (Figure 6). The rigidities were normalized to the secant rigidities at specified curvatures, and results are shown in Figure 9. The secant rigidity values were based on the monotonic tests (Figure 4). The normalization collapsed most of the fatigue curves into the top zone showing an around 65\% rigidity drop for these rods before the final failure. On other hand, ZRAP10 and ZRAP15 displayed a much lower value of normalized rigidity because of initial structural modifications.

It is interesting to see from Figure 9(b) that the phase of rigidity as defined below was generally quite stable in the cyclic process, at around -6 degrees,

$\phi_{R}=\phi_{M}-\phi_{\kappa}$,

where $\phi_{\mathrm{M}}$ is the phase angle of moment and $\phi_{\mathrm{k}}$ is the phase angle of curvature. This seems to indicate that the increase in hysteresis observed above was mainly due to the increase in

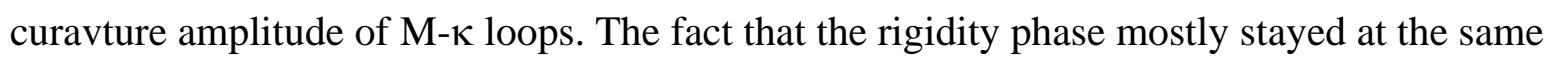
level may signify a persistent fatigue mechanism involved with the cyclic process.

The degree of epoxy bonding and filling has an important effect on the performance of rod under bending. As mentioned above, a static bending test was conducted on a surrogate rod that included alumina pellets but with no epoxy bonding to highlight the effects of PCI/PPI configurations on the bending resistance of rod. A significant decrease was indeed observed in 
secant rigidity (ZRAPM01 in Figure 4); at $0.5 \mathrm{~m}^{-1}$, the drop was amounted to $50 \%$. The significant difference revealed should explain the marked variation of initial rigidity values among the rods tested (Figure 6). This was validated by the optical microscope study, for instance, nonuniform epoxy layers and voids on PPIs/PCIs as seen in ZRAP15 (Figure 8). The contributors to the initial rigidity variation may come from different aspects. In ZRAP15, the structural modification by the momentary ramping, including epoxy debonding, is believed to be responsible for the lowered rigidity. The same observation is also applicable to ZRAP02, which was used to tune the system and for which tripping and a variety of amplitudes occurred prior to the cycling. As demonstrated by the critical role of interfaces in failure mode, PPIs and PCIs would play commeasurable role in the rigidity fatigue of rods. The behavior of PPIs and PCIs in reversed cyclic bending is not quite clear.

Cracking of alumina pellets also contributed to flexural rigidity degradation. The cracking took place because of intensified contact stress on the end faces of pellets. The cracks observed in ZRAP09 obviously resulted from the edge-to-edge contact of neighboring pellets. The resistance of alumina pellets to the compressive loading was compromised accordingly. 


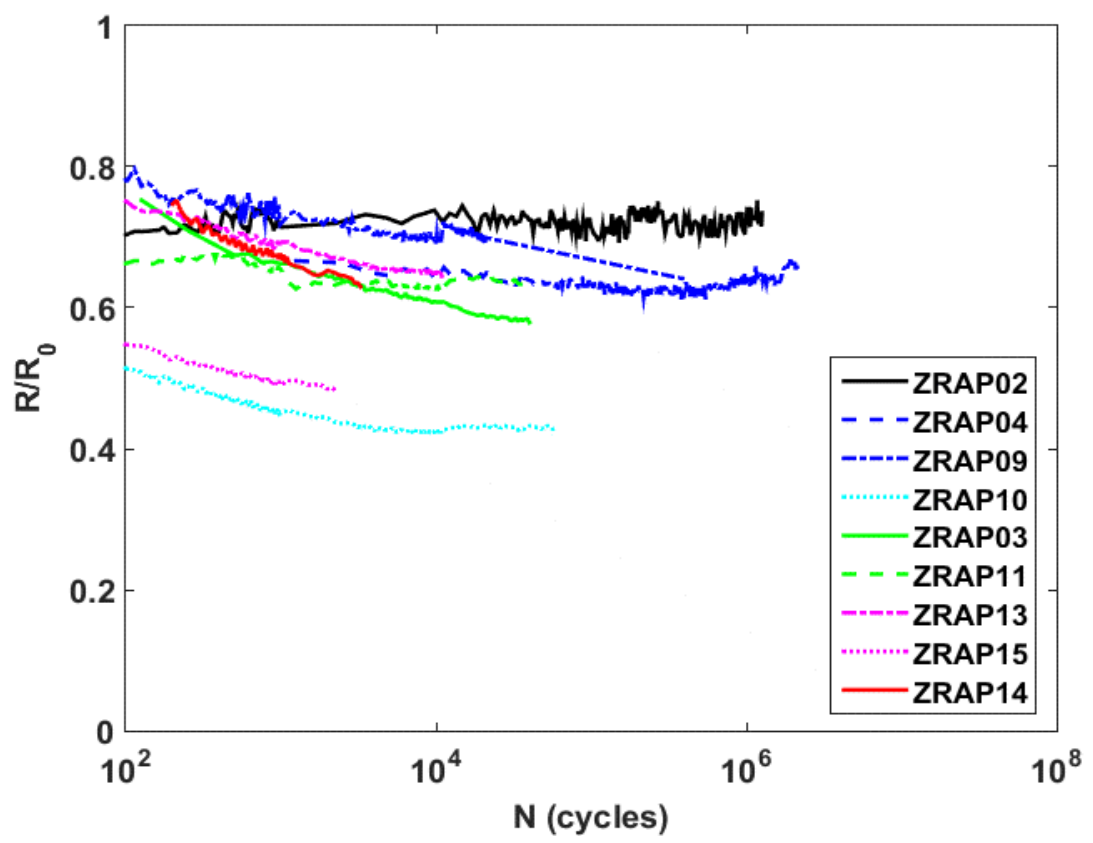

(a)

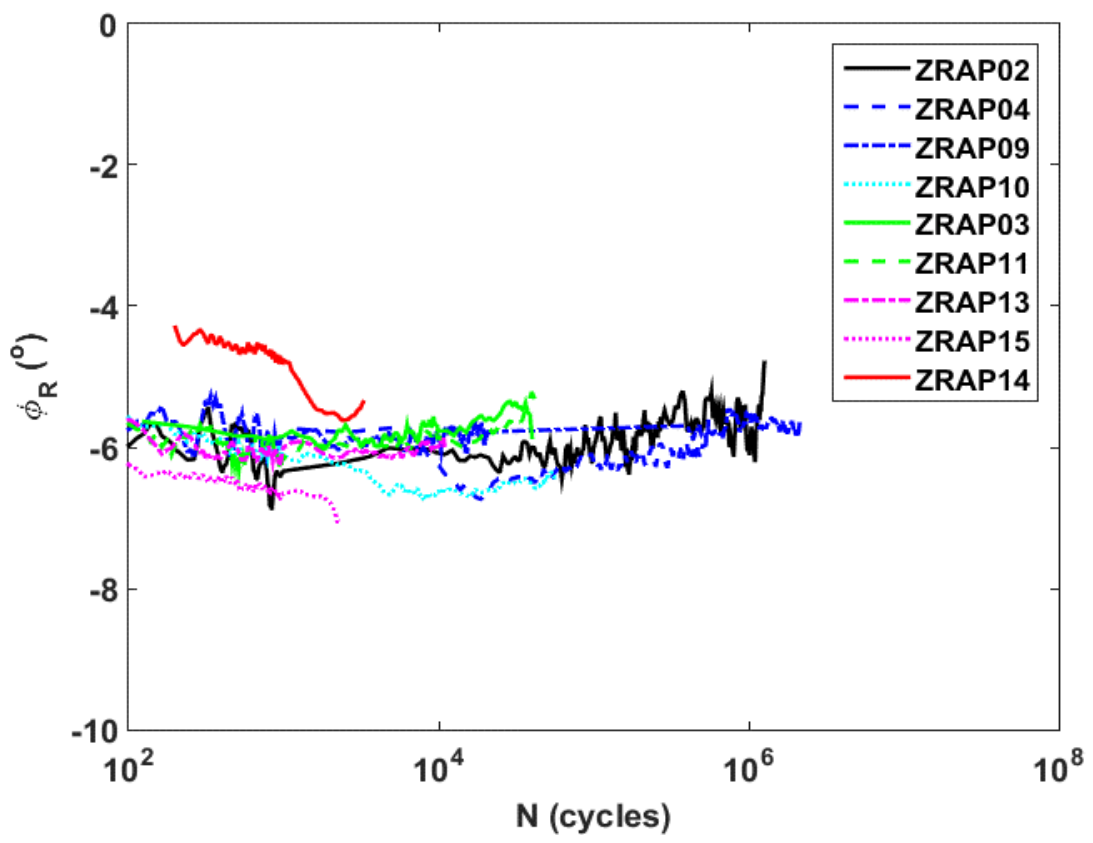

(b)

Figure 9. Variations of (a) normalized rigidity and (b) phase angle as a function of number of cycles. 


\subsection{Crack initiation of cladding}

Fracture may not occur at the location where the stress is the largest, but where large, preexisting flaws are located. The pre-existing structural flaws result from the manufacturing or after-manufacturing material handling and can exist on the surface or inside of cladding. In the case of bending, the transverse flaws normal to the bending or longitudinal axis can become strength-limiting flaws where $\mathrm{K}_{\mathrm{I}}$ type fracture is involved. The role of inner and outer transverse flaws on the failure of cladding was studied previously, and the results can be found elsewhere $[2,19]$.

The stress intensity factor range $\Delta \mathrm{K}_{\mathrm{I}}$ can be evaluated by using the flaw size identified on the fracture surfaces. For a surface crack whose depth is $a$ and length is $2 c$ [20], $\Delta \mathrm{K}_{\mathrm{I}}$ can be expressed by the following equation,

$\Delta K_{I}=Y \sigma_{a} \sqrt{a}$,

where $\mathrm{Y}$ is the stress intensity shape factor, about 1.99 when $\mathrm{c}>\mathrm{a}$, and $\sigma_{\mathrm{a}}$ is the stress amplitude that can be estimated by

$\sigma_{a}=\frac{\Delta M}{2} \cdot \frac{E_{c} y}{R}$

where $\mathrm{E}_{\mathrm{c}}$ is elastic module of cladding same as in Sect. 4.2, $\mathrm{y}$ is the distance to the neutral axis, and other parameters are defined above. The surface flaws of ZRAP09 and ZRAP15 had a narrow band so that 1.99 can be used as a stress intensity shape factor. In addition, a is approximately $75 \mu \mathrm{m}, \mathrm{E}_{\mathrm{c}}=80 \mathrm{GPa}$, and $\mathrm{R}=47 \mathrm{Nm}^{2}$. The $\sigma_{\mathrm{a}}$ values at the crack initiation sites of the two rods were estimated as 108 and $205 \mathrm{MPa}$, and $\Delta \mathrm{K}_{\mathrm{I}}$ values shown to be 1.87 and 3.54 
$\mathrm{MPa} \cdot \mathrm{m}^{1 / 2}$, respectively. The $\Delta \mathrm{K}_{\mathrm{I}}$ values obtained were either within or above the threshold value $\Delta \mathrm{K}_{\text {th }}$ reported for the Zry-4 cladding, 1.2 to $2.2 \mathrm{MPa} \cdot \mathrm{m}^{1 / 2}$ [7]. For ZRAP02 under $10.16 \mathrm{Nm}$, the $\Delta \mathrm{K}_{\mathrm{I}}$ would stay below the threshold value if the same flaw size were taken, so the rod sustained the designated number of cycles without failure. It is noticed that the analysis of stress intensity factor range simplified the surrogate rod by disregarding the difference of materials and interfaces. The cladding also experiences the hoop stress arising from ovalizing [2] and radial stress from PCMI $[8,9]$. The cladding is likely subjected to a mixed-mode loading, and the contribution of $\mathrm{K}_{\mathrm{III}}$ and/or $\mathrm{K}_{\mathrm{II}}$ can be significant. The investigation of these issues demands more advanced numerical technique.

\subsection{Implication}

The fatigue mechanism of SNF rods under transportation environment remains to be explored. To study this and other technical issues on SNF rods in hot cell has not been shown to be feasible in terms of setup accessibility, fuel availability, and operational cost. Use of surrogate rods has been seen to be effective in addressing this challenge. Particularly, it has been demonstrated that the surrogate rods made of Zry-4 cladding and alumina pellets can capture major failure mechanisms like PCMI as observed in high burnup SNF rods. This is significant because that suggests that testing and characterization approaches developed by using surrogate rods may be migrated onto real fuel rods.

The fatigue-induced degradation of flexural stiffness is generally characterized by a primary stage, a secondary stage, and a tertiary stage. The evolution of material structure associated with the fatigue stages was described $[21,22]$. The characteristics of stiffness fatigue are applicable to the fatigue of flexural rigidity. The primary stage of fatigue was usually not seen when 
conducting in this study, because ramping load amplitude to a designed level took a certain amount of time. The secondary stage is extended over most of the fatigue process; fatigue of material in this stage is generally attributed to microcrack activities in pellets and cladding and debonding of PPIs and PCIs as mentioned above. On the other hand, the tertiary stage is quite short for the surrogate rods because the propagation of crack is unstable under load control. Nevertheless, the curvature response of rods in a cyclic test can be characterized by a linear relation of logarithmic number of cycles. The rigidity fatigue response can be predicted readily by using the linear relation, provided that the moment amplitude is given. It has been shown in Figure 9 that the surrogate rods would be categorized according to the prefatigue structural condition; for those located in the top zone, a failure criterion can be established based on the $65 \%$ rigidity ratio. The fatigue characterization approach developed, in cooperation with failure criterion, would enable the lifetime of rods to be predicted in future.

\section{Conclusions}

Monotonic and reversed cyclic bending tests were conducted on surrogate rods made of a Zry-4clad tube and alumina pellets. Two conditions were investigated: one in which the alumina pellets are bonded inside the cladding, and another in which the pellets are unconstrained. The conclusions drawn based on the test results and data analysis are as follows:

The surrogate rods with epoxy bonding fractured under cyclic bending for amplitudes greater than $10.16 \mathrm{Nm}$ with lives between $2.4 \times 10^{3}$ and $2.2 \times 10^{6}$ cycles. No failure was seen at $10.16 \mathrm{Nm}$ after more than one million cycles. A trend between fatigue life and moment amplitude was observed. 
The PPI and PCI dominated the failure of the rod under reversed cyclic bending. The failure of cladding generally occurred near one of the PPIs and was originated from either the inner or outer surface of Zry-4 cladding.

There was a degradation of flexural rigidity under reversed cyclic bending, which amounted to about $65 \%$ of static secant flexural rigidity in most of the tested surrogate rods (Figure 9). The degradation was related to the applied moment amplitude and the pre-existing condition of the rod. An understanding of such factors is helpful for online monitoring of rod performance and predicting rod fatigue life.

\section{Appendix: Curvature calculation and sensor spacing correction}

Curvature of a bending rod can be estimated through a three-point circle equation. Given the deflections from three LVDTs, $d_{1}, d_{2}$, and $d_{3}$, as shown in Figure A1, the curvature $\kappa$ can be evaluated as follows:

$\kappa=\left[x_{0}^{2}+\left(y_{0}+d_{2}\right)^{2}\right]^{-1 / 2}$,

$\mathrm{x}_{0}$ and $\mathrm{y}_{0}$ are the coordinates of center of the circle and given by

$$
\begin{aligned}
& x_{0}=\frac{1}{m_{a}}\left(y_{0}+\frac{d_{1}+d_{2}}{2}\right)-\frac{h}{2}, \\
& y_{0}=\frac{2 m_{a} m_{b} h+m_{a}\left(d_{2}+d_{3}\right)-m_{b}\left(d_{1}+d_{2}\right)}{2\left(m_{b}-m_{a}\right)},
\end{aligned}
$$

where 
$m_{a}=\frac{h}{d_{2}-d_{1}}, \quad m_{b}=\frac{h}{d_{3}-d_{2}}$

and $h$ is the sensor spacing, $12 \mathrm{~mm}$.

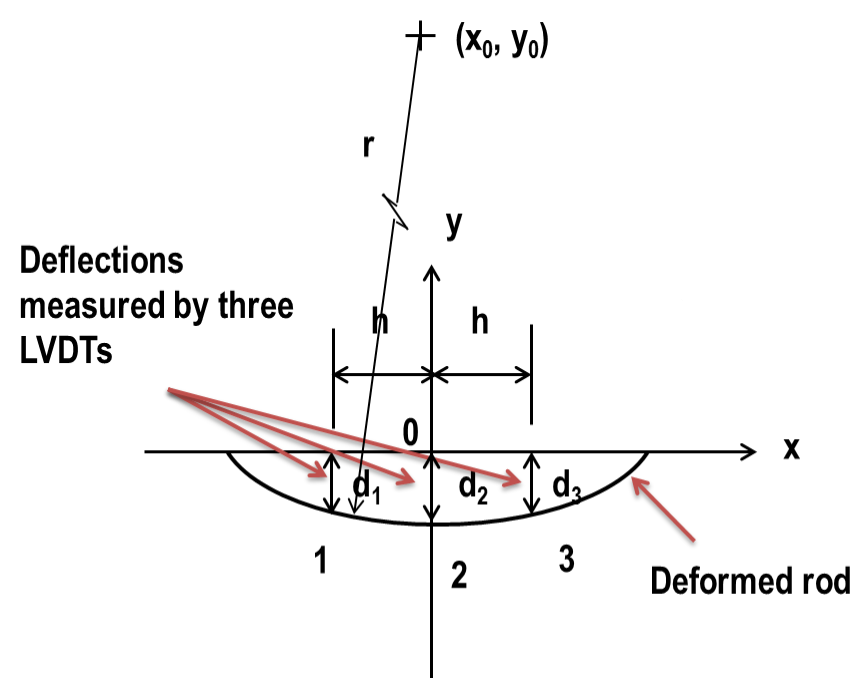

Figure A1 Determination of curvature of the rod by use of deflections measured at three points.

In the cyclic bending test, a disk shape of LVDT probe is used to ensure a reliable contact with rod in measurement and online monitoring. The contact points of LVDTs on the left and right may change as shown in Figure A2, depending on bending direction and induced curvature. This results in the deviation of sensor spacing from the ideal condition.

For positive curvature, actual sensor spacing $h_{2}$ is

$h_{2}=h+\Delta h$

and for negative curvature, actual sensor spacing $h_{1}$ is

$h_{1}=h-\Delta h$ 
In order to use Eq. (A1) in the calculation of curvature, the sensor spacing correction $\Delta \mathrm{h}$ needs to be determined.

A chisel shape of LVDT probe may be used. However, uncertainty exists because the measurements were usually conducted in different sessions and contact conditions may be changed. In this appendix, a correction method based on the equal gauge length concept is introduced. In fact, an effective half-gauge length of the rod, $\mathrm{L}_{\mathrm{g}} / 2$, can be defined once the deflection $\mathrm{d}_{2}$ and curvature $\mathrm{\kappa}$ are given, or

$$
L_{g} / 2=\sqrt{2 d_{2} / \kappa} .
$$

In the current testing setup, the gauge length is considered same no matter if the rod is bent in positive or negative direction. By applying the Eq. (A3) to the peak and valley values, the equality of half-gauge length results in the following relation,

$d_{2 p}^{+} /\left.\kappa_{p}^{+}\right|_{h_{2}=h+\Delta h}=d_{2 p}^{-} /\left.\kappa_{p}^{-}\right|_{h_{1}=h-\Delta h}$.

The spacing correction $\Delta \mathrm{h}$ can thus be obtained by resolving Eq. (A4).

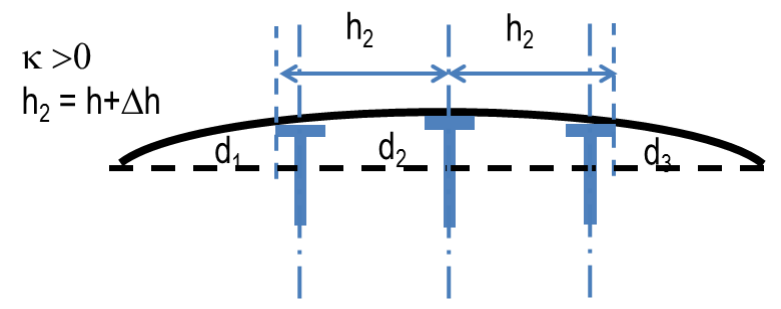

(a) 


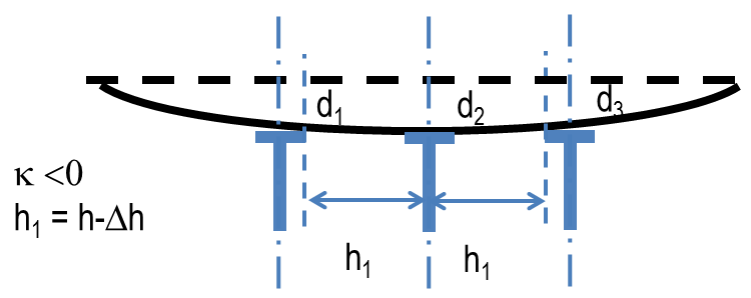

(b)

Figure A2. Deflections measured by LVDTs may be at different points from initial positions in (a) positive and (b) negative curvature, and sensor spacing $h$ needs to be corrected.

A polycarbonate rod (11.11 $\mathrm{mm}$ diameter and $152.40 \mathrm{~mm}$ length) was tested under displacement control to $\pm 6 \mathrm{~mm}$ at each loading point. With the input, the rod is supposed to behave elastically. Note that the flexural rigidity of rod, EI, is $1.80 \mathrm{Nm}^{2}$. So the curvature of rod can be effectively calculated when the moment $\mathrm{M}$ is provided, namely,

$\kappa=M / E I$.

The three LVDT-based curvature curve obtained with disk probe is presented in Figure A3 with and without the correction applied. The correction procedure suggested that a $\Delta \mathrm{h}$ of $2.50 \mathrm{~mm}$ is needed. The corrected curvature showed a good correspondence with the $\mathrm{M}$ - based curvature according to Eq. (A5).

In the monotonic test, $\Delta \mathrm{h}=2.50 \mathrm{~mm}$ obtained from the calibration can be used for spacing correction in data analysis. In the reversed cyclic bending, the $\Delta \mathrm{h}$ can be obtained directly using Eq. (A4) because the peak and valley pair is available in the data block. 


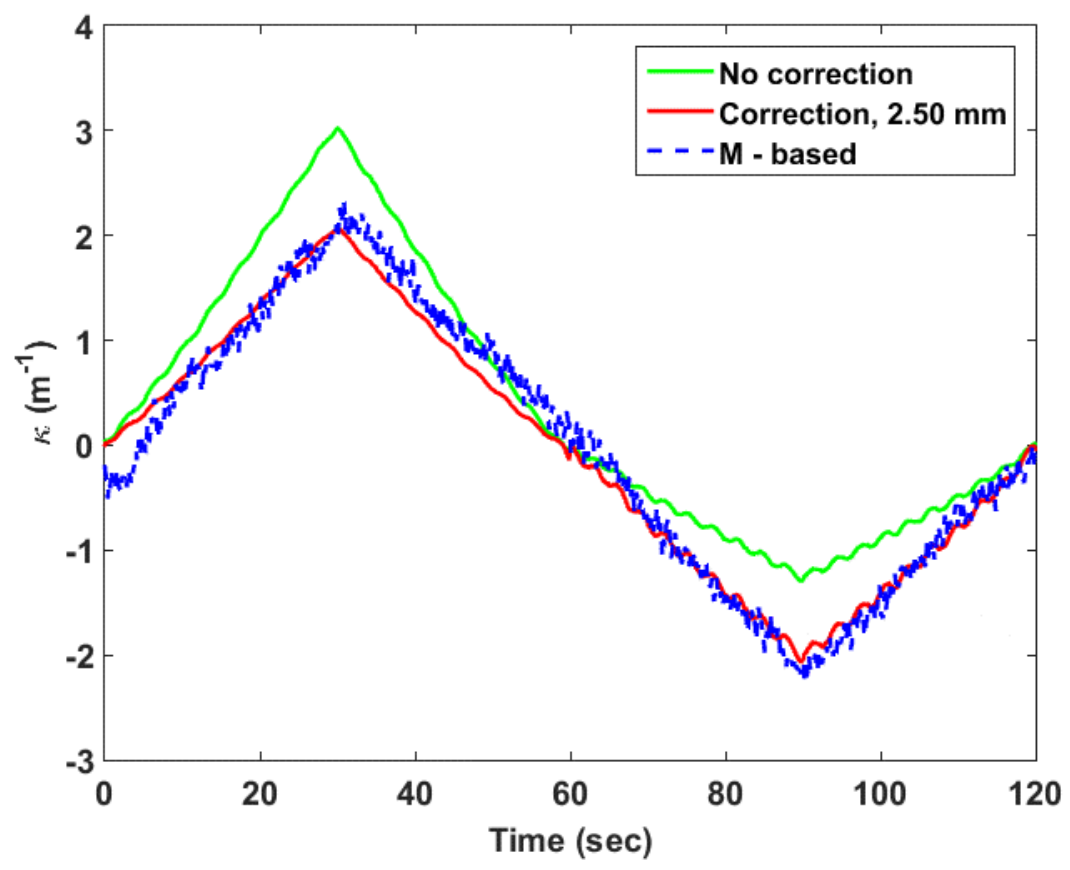

Figure A3. Curvature measurements of polycarbonate rod based on disk type probe, 2.50 mm sensor spacing correction, and $M$ - based estimate.

\section{ACKNOWLEDGMENTS}

The research was jointly sponsored by the Office of Nuclear Regulatory Research, the US Nuclear Regulatory Commission (NRC) and the US Department of Energy (DOE) Used Fuel Disposition Campaign programs under DOE contract DE-AC05-00OR22725 with UT-Battelle, LLC.

The authors would like to thank NRC program managers Michelle Bales and Patrick Raynaud, ORNL program managers Bruce Bevard and Rob Howard, and Pacific Northwest National Laboratory program manager Harold Adkins for providing guidance and support. The authors would also like to thank Dr. Lianshan Lin of ORNL for reviewing this manuscript. 


\section{References}

[1] NRC, General Standards for All Packages, §43(f) in Title 10, Code of Federal Regulations, Part 71, Packaging and transportation for radioactive material, US Nuclear Regulatory Commission, Washington, DC, Dec. 6, 2010.

[2] T. L. Sanders, K. D. Seager, Y. R. Rashid, P. R. Barrett, A. P. Malinauskas, R. E. Einziger, H. Jordan, T. A. Duffey, S. H. Sutherland, P. C. Reardon, A method for determining the spentfuel contribution to transport cask containment requirements, Sandia Report, SANDSO-2406, Sandia National Laboratory, Albuquerque, NM, November 1992.

[3] K. J. Geelhood, C. E. Beyer, W. G. Luscher, PNNL Stress/Strain Correlation for Zircaloy, PNNL-17700, Pacific Northwest National Laboratory, Richland, Wash. July 2008.

[4] W. J. O’Donnell, B. F. Langer, Fatigue design basis for Zircaloy components, Nucl. Sci. and Eng. 20 (1964) 1-12.

[5] K. Pettersson, Low-cycle fatigue properties of Zircaloy-2 cladding, J. Nucl. Mater. 56 (1975) $91-102$.

[6] M. Nakatsuka, T. Kubo, and Y. Hayashi, Fatigue behavior of neutron irradiated Zircaloy-2 fuel cladding tubes, Zirconium in the Nuclear Industry: Ninth Int. Symp., ASTM STP 1132. C. M. Eucken and A. M. Garde, Eds., ASTM, 1991, 230-245.

[7] S. B. Wisner, M. B. Reynolds, and R. B. Adamson, Fatigue behavior of irradiated and unirradiated Zircaloy and Zirconium, Zirconium in the Nuclear Industry: Tenth Int. Symp., ASTM STP 1245, A.M. Garde and E. R. Bradley, Eds., ASTM, Philadelphia, 1994, 499-520. 
[8] T. Fuketa, H. Sasajima, T. Sugiyama, Behavior of high-burn- up PWR fuels with low-tin Zircaloy-4 cladding under reactivity-initiated-accident conditions, Nucl. Technol. 133 (2001) $50-62$.

[9] K. Tomiyasu, T. Sugiyama \& T. Fuketa, Influence of cladding-peripheral hydride on mechanical fuel failure under reactivity-initiated accident conditions, J. Nucl. Sci. and Tech. 44 (2007) 733-742.

[10] T. M. Link, D. A. Koss, and A. T. Motta, Failure of Zircaloy cladding under transverse plane-strain deformation, Nucl. Eng. and Des. 186 (1998) 379 - 394.

[11] M. Le Saux, J. Besson, S. Carassou, C. Poussard, X. Averty, Behavior and failure of uniformly hydrided Zircaloy-4 fuel claddings between $25^{\circ} \mathrm{C}$ and $480^{\circ} \mathrm{C}$ under various stress states, including RIA loading conditions, Eng. Failure Analysis 17 (2010) 683-700.

[12] J.-A. J. Wang, H. Wang, T. Cox, and Y. Yan, Progress letter report on U-Frame test setup and bending fatigue test for vibration integrity study (out-of-cell fatigue testing development Task 2.3), ORNL/TM-2012/417, Oak Ridge National Laboratory, Oak Ridge, TN, August 2012.

[13] H. Wang, J.-A. J. Wang, T. Tan, H. Jiang, T. S. Cox, R. L. Howard, B. B. Bevard, and M. E. Flanagan, Development of U-frame bending system for studying the vibration integrity of spent nuclear fuel, J. Nucl. Mater. 440 (2013) 201-213.

[14] J.-A. J. Wang, H. Wang, T. Cox, C. Baldwin, Progress letter report on bending fatigue test system development for spent nuclear fuel vibration integrity study (out-of-cell fatigue testing development - Task 2.4), ORNL/TM-2013/225, Oak Ridge National Laboratory, Oak Ridge, TN, July 2013. 
[15] J.-A. Wang, H. Wang, B. Bevard, and R. Howard, New rig for studying SNF vibration integrity, Nucl. Eng. Int. 59 (2014), 36-37.

[16] ElectroForce System Group, ElectroForce LM2 TestBench, Test Instrument Reference Manual, Bose Corp., Eden Prairie, MN, 2012.

[17] J.-A. J. Wang, H. Wang, Progress letter report on reversal bending fatigue testing of Zry-4 surrogate rod (out-of-cell fatigue testing development - Task 2.4), ORNL/TM-2013/297, Oak Ridge National Laboratory, Oak Ridge, TN, August 2013.

[18] J.-A. J. Wang, H. Jiang, H. Wang, The impact of interface bonding efficiency to high burnup spent nuclear fuel vibration integrity during normal transportation, ORNL/TM- 2013/296, Oak Ridge National Laboratory, Oak Ridge, TN, August 2013.

[19] I. S. Raju, J. C. Newman, Stress-intensity factors for internal and external surface cracks in cylindrical vessels, J. Pressure Vessel Technol. 104 (1982), 293-298.

[20] J. C. Newman, I. S. Raju, An empirical stress intensity factor equation for the surface crack, Eng. Fract. Mech. 15 (1981) 185-192.

[21] W. V. Paepegem, J. Degrick, A new coupled approach of residual stiffness and strength for fatigue of fibre-reinforced composites, Int. J. Fatigue 24 (2002), 747-762.

[22] M. A. Abojaradeh, M. W. Witczak, M. S. Mamlouk, K. E. Kaloush, Validation of initial and failure stiffness definitions in flexure fatigue test of hot mix asphalt, J. Testing and Eval. 35 (2010), Paper ID JTE100102. 